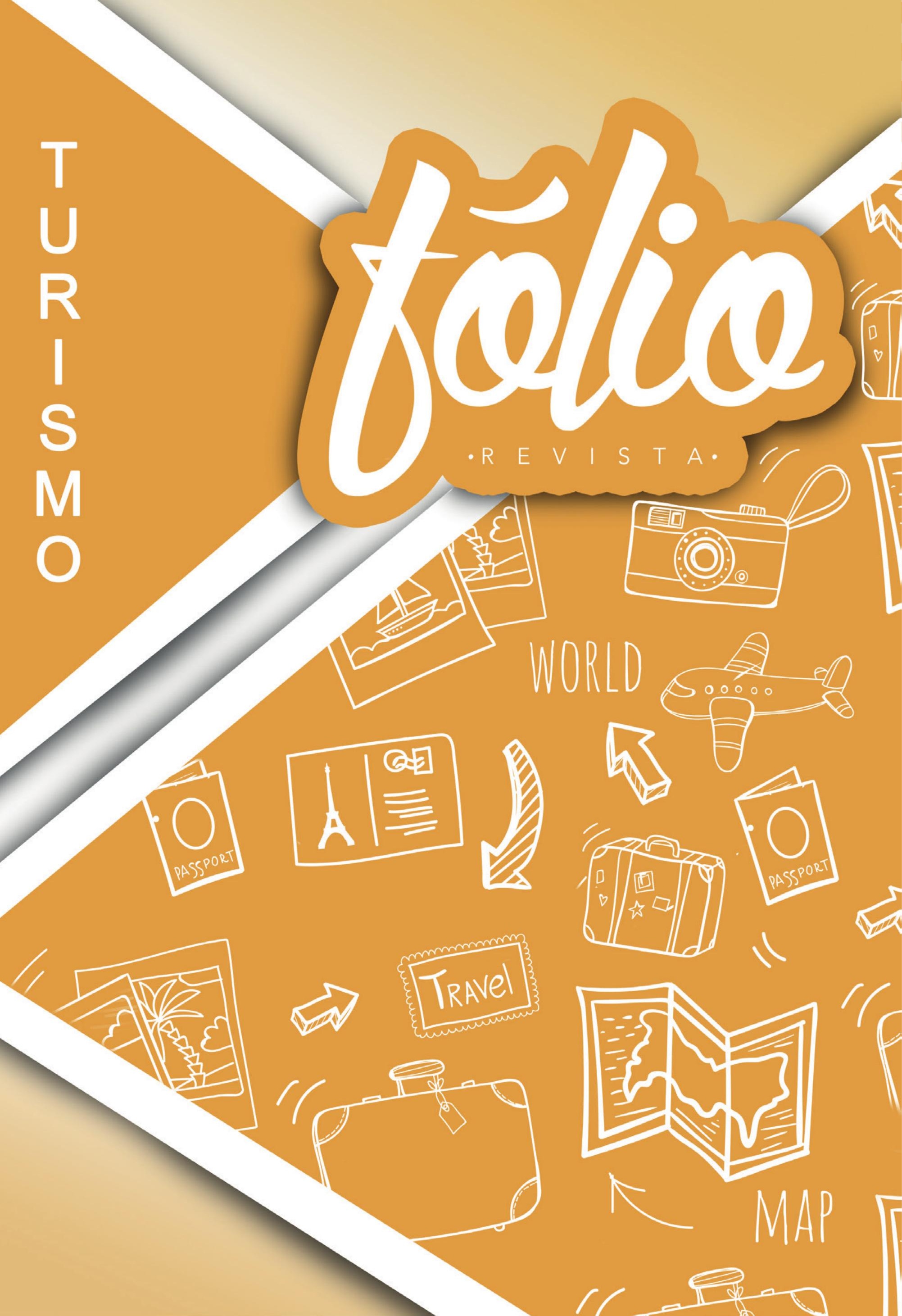




\title{
Potencialidades do desenvolvimento do turismo de observação de baleias no litoral norte do Rio Grande do Sul
}

\author{
Gabriel Sudbrack² \\ Aline Moraes Cunha ${ }^{3}$
}

\section{Resumo}

O objetivo deste artigo foi apresentar os resultados da pesquisa que buscou analisar o potencial de desenvolvimento turístico através da prática de Observação de Baleias, como combate ao período de sazonalidade das praias de Imbé e Torres, localizado no litoral norte do Rio Grande do Sul. Para isso, o trabalho teve como fatores norteadores um objetivo geral e três específicos. Para alcançar os resultados foram realizados questionários em órgãos públicos e atores do segmento. No referencial teórico foram discutidos conceitos de educação ambiental, Ecoturismo e atividade de observação de baleais. Nas considerações finais se apresenta os resultados obtidos e a evidenciação do alcance dos objetivos propostos, em especial a confirmação da potencialidade para a implantação da prática de observação de baleias no Litoral norte do Rio Grande do Sul.

Palavras chaves: Turismo; Observação de baleias, litoral norte, Rio Grande do Sul; Torres; Imbé.

\footnotetext{
1 Artigo resultante do Trabalho de Conclusão de Curso - TCC do primeiro autor, sob orientação da segunda autora, defendido e aprovado no curso de Bacharelado em Turismo do Centro Universitário Metodista - IPA, em 2017.

2 Bacharel em Turismo - Centro Universitário Metodista - IPA. E-mail: gabrielsudbrack@hotmail.com

3 Mestre em Desenvolvimento Rural (PGDR/UFRGS); Pós - Graduada em Agricultura Orgânica (UCS); Bacharel em Turismo (PUC/RS); Docente do curso de Bacharelado em Turismo do Centro Universitário Metodista - IPA. E-mail: alineturdes@gmail.com
} 


\section{Considerações iniciais}

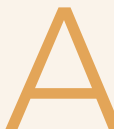

presente pesquisa teve como tema a análise do potencial de desenvolvimento turístico através da prática de Observação de Baleias no Litoral Norte do Rio Grande do Sul. Segundo o Ministério do Turismo - MTUR (2006), o Ecoturismo é um segmento da atividade turística que utiliza, de forma sustentável, o patrimônio natural e cultural, incentiva sua conservação e busca a formação de uma consciência ambientalista através da interpretação do ambiente, promovendo o bem-estar das populações. Sendo assim, é possível identificar a importância do desenvolvimento sustentável para a segmentação mencionada acima. Sendo as cidades de Torres e Imbé duas das principais cidades turísticas litorâneas do estado do Rio Grande do Sul, e tendo em vista a característica de sazonalidade da região pergunta-se: existe potencialidade para o desenvolvimento do ecoturismo através do Turismo de Observação de Baleias no litoral norte do Rio Grande do Sul?

Buscando a resolução do problema apresentado, teve como objetivo geral, averiguar a possibilidade de inserção da observação de baleias como uma atividade de ecoturismo na cidade de Torres e Imbé. Já os objetivos específicos, constituem-se em: investigar e relatar as atividades de ecoturismo, já existentes e comercializadas nas cidades de Torres e Imbé; pesquisar quanto à implantação de um observatório de baleias; considerar a viabilidade da observação de baleias como um atrativo turístico potencial e de alternativa a sazonalidade para os municípios, no que se considera baixa temporada;

Visto que o presente estudo versa sobre a observação de fauna, como atividade do Ecoturismo, que conforme o Ministério do Turismo - MTUR (BRASIL, 2010), é toda atividade relacionada a prática de sustentabilidade com a natureza, comprometida com a conservação e a educação ambiental juntamente a proteção da área realizada. Ressalta-se a relevância do segmento no Brasil, visto que conforme dados da Organização Mundial do Turismo (OMT), o Ecoturismo cresce de 15 a $25 \%$ ao ano, mais que o dobro do turismo convencional no mundo (OMT, 2015).
Colaborando com a compreensão quanto á relevância do presente estudo, podemos destacar o apontamento do Centro de Estudos Costeiros Limnológicos e Marinhos - CECLIMAR da UFRGS, que ressalva o fato do litoral do Rio Grande do Sul (RS) possuir uma das maiores biodiversidades de fauna marinha e costeira do Atlântico Sul Ocidental, abrigando um grande número de espécies de tetrápodes ${ }^{4}$ marinhos. Em conformidade pesquisa realizada pelo Greenpeace ${ }^{5}$, aponta que a observação de baleias gera anualmente 6,5 bilhões de reais, visto que organizações do mundo inteiro trabalham esta atividade, como oferta turística.

Na América Latina no ano de 2007, calculou-se que mais de um milhão de pessoas visitaram as costas latino-americanas em busca de atividade turística. Os bons resultados levaram várias comunidades costeiras, tradicionalmente habitadas por pescadores, a mudar "para se dedicar a esse turismo verde, gerando maiores opções de lucros para elas", afirma (IÑíGUEZ, 2007, np) autor da pesquisa realizada para o G1.

No Brasil segundo o MTUR (2014) podemos observar os cetáceos no litoral da Bahia, no Parque Nacional Marinho de Abrolhos instituído desde 1983 e administrado pelo Instituto Chico Mendes de Conservação da Biodiversidade (ICMBio), e em Santa Catariana na região de Imbituba onde existe uma Área de preservação natural (APA) desde 2003, que conta com $130 \mathrm{~km}$ de preservação.

Conforme averiguação inicial realizada nos sites da Secretaria Municipal de Turismo de Torres, Secretaria de Turismo do Estado do Rio Grande do Sul e Ministério do Turismo, não existe um observatório permanente para a visualização de animais marítimos em terra, nem em embarcações. Desta forma, se verifica que esta seria uma proposta inovadora para a região e para o estado, que além de aumentar a oferta turística das cida-

\footnotetext{
4 Os tetrápodes são animais vertebrados terrestres, que possuem quatro membros. Estes animais pertencem à superclasse

Tetrapoda. Os anfíbios, mamíferos, répteis e aves são tetrápodes (Ceclimar). Disponível em: http://www.ufrgs.br/ceclimar/ceram/ projetos $>$ Acesso em: 20 de set.2016.

5 Greenpeace é uma organização não governamental de proteção do Meio Ambiente. Para conhecer melhor, consultar: http://www. greenpeace.org/brasil/pt/
} 
des de Torres e Imbé, poderia colaborar com o fluxo turístico local, justamente no período de baixa temporada para as cidades, visto que conforme Ely (2015), a observação de Baleias no Atlântico Sul ocorre nos meses de junho a novembro, período em que algumas espécies de baleias vêm para a costa se reproduzir devido às correntes de águas mornas.

Assim sendo, a presente pesquisa, buscou gerar como benefícios mais um elemento de atratividade para as cidades de Torres e Imbé, alavancando o desenvolvimento das atividades de pesquisa e de outros projetos que visem a melhoria da qualidade de vida das comunidades locais. Da mesma forma, destacamos a sua relevância para demais áreas científicas, como a biologia marinha, oceanografia e outras afins.

\section{Referencial teórico}

Para a correta interpretação do estudo realizado, nesta seção apresentamos o referencial teórico, que da embasamento às investigações realizadas, trazendo temas como Turismo e educação ambiental; Ecoturismo; Turismo de observação de fauna e flora; e a Observação de Cetáceos.

\section{Turismo e educação ambiental e o ecoturismo}

Inicialmente cabe destacar a afirmativa de Loureiro (1999, p. 28), que ressalva que a educação ambiental, "não atua somente no plano das ideias e no da transmissão de informações, mas no da existência," em que o processo de conscientização se caracteriza pela ação e pela capacidade de fazermos opções, de assumir um compromisso com a vida.

Neiman e Rabinovici (2002), apontavam ser o turismo uma das atividades econômicas mais importantes do país e uma das que mais cresce, devido a prática do Ecoturismo, seno este "[...] um segmento que utiliza de forma sustentável o patrimônio natural e cultural, incentiva sua conservação e busca a formação de uma consciência ambientalista através da interpretação do ambiente, promovendo o bem estar das populações envolvidas". (NEIMAN; RABINOVICl, 2002, p.146). Os autores já apontavam também a necessidade deste segmento deixar de preparar os locais visitados e passar a preparar as pessoas para conhecerem os locais, já que estas não possuem uma formação adequada. Portanto não saberão respeitar a natureza (NEMAN; RABINOVICl, 2002).

Dias (2003) afirma que não se pode negar que o impacto do turismo sobre o meio ambiente é inevitável. Então o que se pode fazer é manter a atividade dentro dos limites aceitáveis, para que não coloque em risco o meio ambiente, causando danos irreversíveis. Assim os visitantes poderão usufruir melhor do local.

Nesse sentido, consideram que a educação ambiental tem como um de seus objetivos formar cidadãos conscientes de sua relação com a natureza e com seu habitat. Diante disso, apontam que ela, independentemente da metodologia, deve primar pela formação de pessoas conscientes de seu papel e de sua relação com o meio ambiente de modo a promoverem a sustentabilidade, através do uso racional dos recursos naturais, para que tanto esta quanto as futuras gerações possam também deles usufruir (NEIMAN; RABI$\mathrm{NOVICl}, 2002)$.

Neiman e Rabinovici (2002) ainda ressaltam que o principal objetivo da educação ambiental é o desenvolvimento sustentável, que inclui a prática do turismo sustentável. Esta prática visa a meIhoria da qualidade de vida da comunidade receptora e oferece aos visitantes uma experiência enriquecedora, além de manter a qualidade do meio ambiente do qual todos dependem. Para que esta sustentabilidade ocorra é necessário que as pessoas tomem consciência de que se devem preservar o meio ambiente, através de programas de educação ambiental onde todos os envolvidos na atividade turística ou não, devem participar.

Reigota (2006, p.11), destaca que devem ser consideradas "prioritariamente as relações econômicas e culturais entre a humanidade e a natureza e entre os homens". Ele considera que o homem contemporâneo "dificilmente se considera um elemento da natureza, mas como um ser à parte, observador e/ou explorador da mesma." Conforme Reigota (2006, p.58), é preciso reconhecer que: 
[...] a Educação Ambiental é uma das mais importantes exigências educacionais contemporâneas a nível mundial. Que esta não está vinculada apenas à transmissão de conhecimentos sobre a natureza, mas a uma possibilidade de ampliação da participação da população, buscando estabelecer uma nova aliança entre a humanidade e a natureza. (REIGOTA, 2006, p.58).

Havendo esta necessidade deste estabelecimento de uma nova aliança entre a humanidade e a natureza, chegamos à prática do Ecoturismo, que conforme destaca o Ministério do Turismo brasileiro (BRASIL, 2014), é um termo recente na história do turismo, iniciado na década de 1980, é uma atividade turística realizada em lugares naturais, com o intuito de valorização das comunidades locais aonde o turista é responsável ambiente, assim como a sua preservação. Ecoturismo precisa possuir ligação com a natureza.

Segundo Boiteux e Werner (2009), o turismo se divide em dois tipos, sendo atrativos naturais e culturais. O ecoturismo "é uma atividade que compreende em si um posicionamento ambiental de conservação do patrimônio natural e cultural, tanto em áreas naturais como em não naturais." (COSTA, 2002, p. 15).

Para Pires (2002), o Ecoturismo está diretamente ligado a educação ambiental, visando o aprofundamento da consciência ecológica e respeito aos valores tanto da comunidade local quanto dos turistas.

Segundo a World Wide Found for Nature WWF (2003), o Ecoturismo se bem planejado e desenvolvido, pode trazer às populações locais benefícios amplos, como oportunidades de diversificação e consolidação econômica, geração de empregos, conservação ambiental, valorização da cultura, conservação e/ou recuperação do patrimônio histórico, recuperação da autoestima, entre outros.

Segundo Brasil (2010) o Ecoturismo é um segmento da atividade turística que utiliza, de forma sustentável, o patrimônio natural e cultural, incentiva sua conservação e busca a formação de uma consciência ambientalista por meio da interpretação do ambiente, promovendo o bem-estar das populações, no caso, turismo e educação ambien- tal, contemplando atividades de observação de fauna e flora, e contribuindo com a conservação do meio ambiente, como abordaremos na próxima seção.

\section{Turismo de observação de fauna e flora}

Conforme Carvalho (1978), desde os primórdios da humanidade, a observação de fauna e flora é uma importante atividade, seja para a obtenção de alimento ou simplesmente pelo prazer de contemplar os animais. $\bigcirc$ autor ainda ressalta a observação não é, necessariamente conflitantes com a conservação da natureza, desde que seja desenvolvida em bases sustentáveis e destaca que recentemente, a fauna e flora passou a ter um outro valor econômico, o de atrativo turístico.

Oliveira e Cassaro (1997) explicam que em virtude do crescimento da degradação ambiental em todo o planeta, muitos passaram a caçar animais apenas com binóculos, filmadoras e máquinas fotográficas, visto que conhecer os animais e seus hábitos é uma atividade estimulante e intrigante. Com o fortalecimento do movimento ambientalista, um número crescente de estudiosos e amantes da natureza passou a se interessar pela fauna silvestre. $O$ ecoturista, experiente ou iniciante, aprecia a observação de fauna de uma maneira geral, particularmente quando obtém maiores informações sobre os animais observados.

Segundo Brumatti (2008), a importância atribuída ao crescimento do Whale Watching ${ }^{6}$ e demais atividades de observação da fauna está diretamente relacionada aos seguintes fatos: geração de renda e emprego com uma melhor distribuição, o uso não letal dos animais, o que colabora com a conservação das espécies e com a possibilidade de trabalhar com a educação ambiental com todos os agentes envolvidos; auxílio para pesquisa científica em diversas áreas.

O turismo de observação da vida selvagem representa um segmento turístico que envolve a

6 Observação de baleias. 
apreciação de animais em seu habitat natural. A apreciação ocorre, através da observação, porém em alguns casos pode envolver interações com os animais, como o toque e oferecimento de alimento (UNEP/CMS, 2006). Para fins deste estudo, destacamos a observação de cetáceos, a ser abordada na próxima seção.

\section{Observação de cetáceos - as baleias}

Para o correto entendimento desta seção, se faz necessário o esclarecimento inicial quanto aos cetáceos, centro desta pesquisa. De acordo com a autora Jacobina (2000), cetáceos são mamíferos aquáticos mais comumente encontrados em mares, mas podem ser achados em rios e estuários, fazem parte desse grupo baleias, botos e golfinhos.

Segundo Hoyt (2001) o Ecoturismo começou a praticar a observação de cetáceos, devido ao a redução de população das baleias em todo o mundo. $O$ autor ainda ressalta, o número de observadores de cetáceos, entre 1991 a 1998 que passou de 4 milhões a 9 milhões de pessoas, um acréscimo de cerca de $12,1 \%$ ao ano. Os países que demonstram maior participação são os Estados Unidos, Canadá, Ilhas Canárias (Espanha), Austrália e África do Sul.

Conforme Dias e Aguiar (2002), a observação de baleias virou um negócio bilionário que, em alguns países ficou mais lucrativo do que a caça de baleias, conforme do Fundo Mundial para a Natureza (WWF). Um exemplo é a Islândia, pois o crescimento da atividade de observação em dez anos, foi de 100 a 44 mil pessoas. Hoty (2001) ressalta que $72 \%$ do turismo de observação de baleias é realizado por embarcações, como barcos, navios e lanchas e apenas $28 \%$ ocorre em terra firme.

De acordo com Roe (1997), em geral, o Whale Watching ocorre, principalmente, em áreas cruciais de parte da história natural destes animais. Como as rotas migratórias ou áreas de alimentação e reprodução, que tornam o encontro mais garantido. Ao mesmo tempo, por serem áreas de grande relevância para os animais. Pode-se alte- rar e ou perturbar todo o comportamento característico das espécies e assim interferir em sua sobrevivência.

Brumatti (2013) aponta que a grande preocupação em relação ao turismo de observação das Jubartes em todo o mundo está relacionada a fatores como: intenso tráfego de embarcações turísticas; estreita proximidade destes barcos sobre as baleias que estão muitas vezes acompanhadas de seus filhotes nas áreas de reprodução; poluições sonoras, que podem provocar mudanças nos padrões da sonorização produzida por elas para a comunicação.

Conforme destacado por Oliveira (1997), para que o turismo não colabore com a destruição das populações de animais silvestres é preciso ética na sua observação, ressaltando que a ética se refere a uma conduta, ou postura correta do ser humano. E destaca ser fundamental o respeito pelos animais que se pretende observar, evitando perturbá-los, pois um animal pode abandonar seu ninho e, até mesmo, deixar de frequentar um local, caso se sinta ameaçado pela presença do homem.

Carvalho (1978) ressalta que algumas estruturas podem facilitar a observação de animais silvestres, permitindo a aproximação a locais de difícil acesso. Torres, passarelas suspensas e equipamentos de escalada permitem a observação das copas das árvores, onde se concentra grande parte da atividade animal nas florestas. Passarelas ou decks permitem o acesso a locais alagadiços, como mangues, veredas, igapós e florestas inundadas. Essas estruturas podem revelar toda a beleza e riqueza desses ambientes, valorizando-os como atrativos turísticos. No entanto, o planejamento e a instalação desses equipamentos devem ser feitos por pessoal qualificado, garantindo segurança e evitando grandes impactos.

Cabe destacar que para a Observação de Baleias, existem duas formas mais comuns de observação, sendo a observação embarcada e a terrestre. A observação em embarcações é a mais comum em todo o mundo, pois a chance de avistar os cetáceos é maior. As embarcações, conforme exposto na Figura 1, tem que respeitar normas para não prejudicar a vida marinha e não afastar os animais de seu trajeto. (BRASIL, 2002). 
Figura 1 - Observação embarcada na praia de Imbituba - Santa Catariana, Brasil

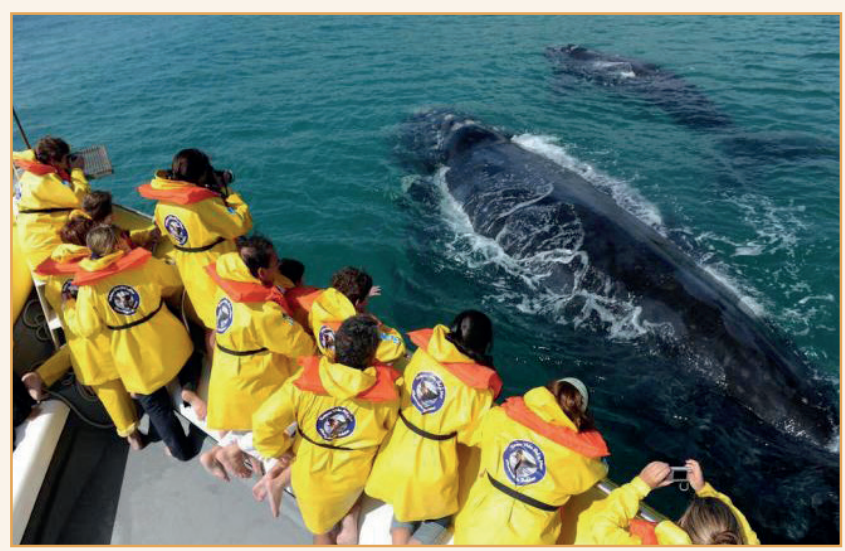

Fonte: Guerra (2016).

As embarcações são realizadas em barcos de grande, médio ou pequeno porte, isso depende do número de pessoas que querem realizar a observação no dia. Todos os turistas devem estar de coletas salva vidas, assim como eu roupa impermeável com a identificação da empresa prestadora de serviço.

\section{Figura 2 - Observatório Terrestre}

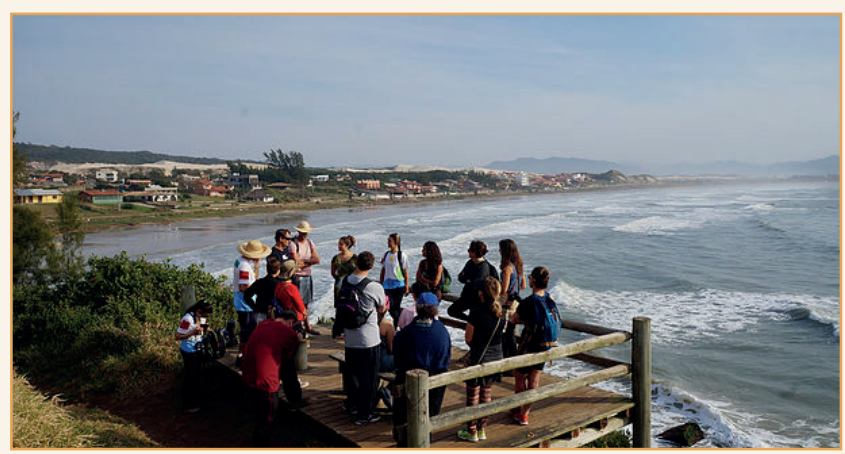

Fonte: Rede Web de Comunicação (2016).

A observação por terra, como apresentado na figura 2, tem sido cada vez mais procurada, pois além de poder avistar as baleias, se faz uma caminhada entre diversas praias, no qual o roteiro é definido pelos organizadores. Conforme observado nos relatos e postagens do grupo TOB Terra - Turismo de Observação de Baleias por Terra (2006), a ser apresentado no próximo capítulo, para realizar esta atividade é necessário um guia especializado, que faz uso dos mirantes dispostos ao longo do trajeto nas praias, bem próximos à costa, e contando com o auxílio de binóculos, disponibilizados para melhor visualização do animal.

Sendo assim, no capítulo a seguir será exposto a respeito do objeto de estudo do artigo apresentado e sua potencialidade para o desenvolvimento turístico. Relatado sobre a atividade de observação de baleias no Brasil e no mundo e sobre a criação de um santuário.

\section{Objeto de estudo - a observação de baleias no mundo}

A atividade de observação de baleias para fins turísticos teve seu inicio nos anos 1950. Segundo Hoty (1995), foi em 1955 que ocorreu a primeira operação turística para a observação de baleias, onde em troca de um Dólar, os curiosos eram levados a observar as baleias cinza na costa de San Diego, Estados Unidos. Hoty (1995) ainda ressalta que foi no inicio dos anos 1970 houve a primeira viagem em grupo organizada pela a sociedade de Zoologia de Montreal teve como destino St. Lawrence no Canadá. Hoje, os países que mais procurados para o turismo de observação de baleias são Estados Unidos, Canadá, Ilhas Canárias (Espanha). Austrália e África do Sul. Foi a partir dos anos 80 que atividade de observação de baleias se difundiu no restante do mundo, inclusive no Atlântico Sul.

De uma maneira geral, atualmente, as principais espécies utilizadas no mundo para a observação são as baleias jubarte, franca, azul, minke e cachalotes, mas a observação de orcas e alguns golfinhos também se têm mostrado relevantes em alguns países (CORBELLI, 2006). De acordo com Hoyt (2001), o número de observadores de baleias, entre 1991 a 1998, passou de 4 milhões a 9 milhões de pessoas, um acréscimo de cerca de $12,1 \%$ ao ano.

Segundo Palazzo (2005) o Atlântico Sul foi vítima por muitos anos de uma caça ilegal de baleias, por se tratar de uma região de migração de algumas espécies, principalmente a baleia Jubarte, sendo assim, foi proposto por diversas organizações sem fins lucrativos em diversos países, a realização de um santuário de baleias, a ser descrito na próxima seção. 


\section{Projeto de criação do santuário}

Segundo WWF (2003) durante o século XX, cerca de 2,9 milhões de baleias foram mortas em todo o mundo, levando a diminuição de baleias em todos os oceanos, sendo que aproximadamente $71 \%$ das baleias caçadas foram mortas no hemisfério sul. Diante disso, para garantir a recuperação das populações de baleias, foi proposta, desde 1998, a criação do Santuário de Baleias do Atlântico Sul, explica a organização do GREEPEACE (2007). Porem o projeto nunca chegou a acontecer devido à oposição de países que fazem parte da Comissão Internacional de Baleias (CIB), como Japão e Noruega.

Segundo Palazzo (2006) o santuário tem como objetivo maximizar a taxa de recuperação de populações de baleias até atingirem seus níveis naturais Promover a conservação a longo prazo das grandes baleias durante seu ciclo de vida e de seus habitat, estimular a pesquisa coordenada na região, especialmente por países em desenvolvimento e desenvolver o uso econômico sustentável e não letal de baleias para o benefício das comunidades costeiras da região.

O Greenpeace ainda ressalta que nesse ano de 2016, foi elaborado um plano de manejo com base nas recomendações do comitê científico da Comissão Baleeira internacional (CBI), um grupo de países formado por Brasil Argentina, Uruguai, África do Sul e Gabão submeterá a criação de um santuário. Com base no estudo acima, a próxima seção discorre sobre a observação de baleias no Brasil e locais nos quais se pode avistar legalmente, os animais.

\section{Observação de baleias no Brasil}

Segundo Brasil (2008) o Ecoturismo, surge no Brasil como uma proposta de apreciação e proteção da natureza, sendo o país com a maior biodiversidade no mundo, no que consiste em: Amazônia, Mata Atlântica, Campos Sulinos, Caatinga, Cerrado, Pantanal e Zona Costeira e Marítima.

Sendo assim, surge a atividade de observação de Fauna, que consiste em analisar, identificar e observar animais e seus habitat natural. Nos últi- mos anos no Brasil vem se destacando a observação de baleias realizadas por embarcações, ou até mesmo por terra no nordeste e sul do país, como verificamos na subseção seguinte.

\section{Observação de Baleias}

em Abrolhos - Bahia

No Brasil existem dois lugares para a prática de observação de baleias. No estado de Santa Catarina, com as Baleias Francas ${ }^{7}$, e no estado da Bahia com as Baleias Jubarte ${ }^{8}$, mais precisamente no Parque Nacional de Abrolhos criado em 1988, após o decreto da lei de proteção às baleias no Brasil. A ocorrência das Jubarte na costa da Bahia passou a ser objeto de estudo entre os pesquisadores, através de um projeto de seu monitoramento. Isto se deu ao redor da região do Arquipélago de Abrolhos, considerado o mais importante sítio reprodutivo da espécie da costa oeste do Atlântico Sul, por representar a maior área de concentração das Jubarte (ENGEL, 1996; MARTINS et. al., 2001), e que se dá no período de juIho a novembro.

Brumati (2002) explica que a atividade de turismo de observação de baleias no parque começou somente a partir do ano 2001, pois as agências e operadoras de turismo passaram a enxergar e considerar este tipo de atividade uma boa alternativa de investimento. Desta forma possibilitando transformar as baleias no atrativo principal dos passeios oferecidos.

Segundo Ministério do Turismo - MTUR (BRASIL, 2014), o parque possuí $913 \mathrm{~km}^{2}$ formado por cinco ilhas: Redonda, Siriba, Guarita, Sueste e o Recife dos Timbebas. Para os turistas chegarem até o parque, somente por embarcações, saindo do município de Caravelas á $70 \mathrm{~km}$ do arquipélago. Existem empresas especializadas e certificas que oferecem esse tipo de turismo em quase todo o litoral do estado. No ano de 2014, mas de 15mil turistas passaram pela região, explica MTUR (BRASIL, 2014).

\footnotetext{
7 Eubalaena Australis.

8 Megaptera Novaeangliae.
} 
O MTUR (BRASIL, 2014) ainda ressalta que existem regras para o avistamento. As embarcações têm que ter distancia de 100 metros do animal e o motor desligado. Brumatti (2002), que já alertava que regras devem ser cumpridas para não espantar o animal ou perturbá-lo de alguma forma e a observação só pode ser realizada em embarcações, diferentemente do realizado no estado de Santa Catarina, a ser apresentado na próxima seção.

\section{Projeto TOB Terra Santa Catarina}

De acordo com a página oficial do Turismo de Observação de Baleias por Terra (TOBE TERRA, 2016), o projeto é formado por entidades que visam desenvolver Turismo de Base Comunitária em Garopaba - SC, tendo em vista a sustentabilidade do local, preservando a natureza da cidade e as culturas tradicionais. Nos roteiros há trilhas ecológicas, observação de baleias e visitas as comunidades tradicionais da cidade, onde o turista vivencia a cultura local, além do contato com a natureza.

Conforme notícia divulgada pelo Diário Catarinense (2014) o projeto de Turismo de Observação de Baleias realizado por terra teve iniciativa a partir da proibição de observação em embarcações, visto que no final de 2012 o turismo de observação de baleias em Santa Catarina foi denunciado pela ONG de proteção aos mares, Instituto Sea Shepherd. ${ }^{9}$ A denúncia foi realizada através de fotos divulgadas de turistas tocando nos animais, sendo que a lei $n^{\circ} 7643$, de 18 de dezembro de 1987 determina uma distância de 100 metros entre o barco e o animal.

Sendo assim, foi criada uma Área de Preservação Ambiental da Baleia Franca (APABF), a qual abrange $130 \mathrm{~km}$ no do litoral de Santa Catarina. Diversos pesquisadores e biólogos chegaram à conclusão, de que a atividade de observação de baleis seria melhor por terra, pois:

\begin{abstract}
A baleia-franca é a única que usa enseadas fechadas para a reprodução. São espaços restritos e rasos, onde elas se sentem protegidas. Nesses lugares reservados, orcas e tubarões não conseguem atacar os filhotes. A pouca profundidade garante proteção e, em princípio, deveria garantir também tranquilidade. (Universidade Federal de Santa Catarina - UFSC, 2016, n/p)
\end{abstract}

Seguindo esta premissa o Instituto Chico Mendes de Conservação da Biodiversidade (ICMBIO), condutores ambientais autônomos junto com o Instituto Federal de Santa Catarina (IFSC), a Associação de Desenvolvimento Territorial Costa Catarina (ADTC), a Associação Amigos do Meio Ambiente para a Ecologia, Desenvolvimento e Turismo Sustentável (AMA), e o SEBRAE/SC, criaram o Turismo de Observação de Baleias por Terra (TOB TERRA), que oferta três tipos de produtos turísticos, sendo eles:

a) Receptivos culturais das comunidades de artesãos, da pesca artesanal e da agricultura familiar;

b) Trilhas ecológicas acompanhadas por condutores ambientais locais;

c) Observação terrestre de Baleias Francas.

Sendo assim, a subseção a seguir expõem o litoral norte do Rio Grande do Sul como uma potencialidade para o desenvolvimento na realização do TOB.

\section{Litoral Norte do Rio Grande do Sul - Potencialidade}

Segundo a Fundação Estadual De Proteção Ambiental (FEPAM) 2002, o Litoral Norte do Rio Grande do Sul possui $3.700 \mathrm{~km}^{2}$ com extensão de 120 km. É integrado por 19 municípios, com economia voltada para à atividade turística de veraneio. A fundação ainda explica:

Trata-se de uma região de idade geológica recente, cujos ecossistemas apresentam características de fragilidade e raridade, mostrando uma seqüência de ambientes de especial valor

9 Para saber mais, consulte: http://seashepherd.org.br/ 
paisagístico e produtividade biológica: praias marinhas, barreiras de duna, banhados, cordão de lagoas doces e salobras e encosta da serra (FEPAM, 2015).

Segundo o Plano de Desenvolvimento do Turismo do RS 2012-2015 (RIO GRANDE DO SUL, 2012) a principal atração da região é a temporada de veraneio, que caracteriza as praias do litoral norte como destino principal para o turismo. Sendo a atividade turística uma das principais economias na região mencionada. Há também um crescente fluxo de turistas nacionais e internacionais. Assim, demarcando uma grande concentração de turistas nos meses de verão e feriados, gerando alta sazonalidade no setor (SETUR, 2012). Além do turismo de sol e praia e de veraneio o Ecoturismo e o turismo de aventura também se fazem presente na região, tais como Mountain Bike, moto trilha, Jeep Cross, trilhas para caminhadas prática do surf e áreas para observações (mirantes). Através do mapa apresentado na figura 3, podemos perceber a extensão do litoral norte do RS.

Figura 3 - Mapa do Litoral

Norte do RS, área de estudo

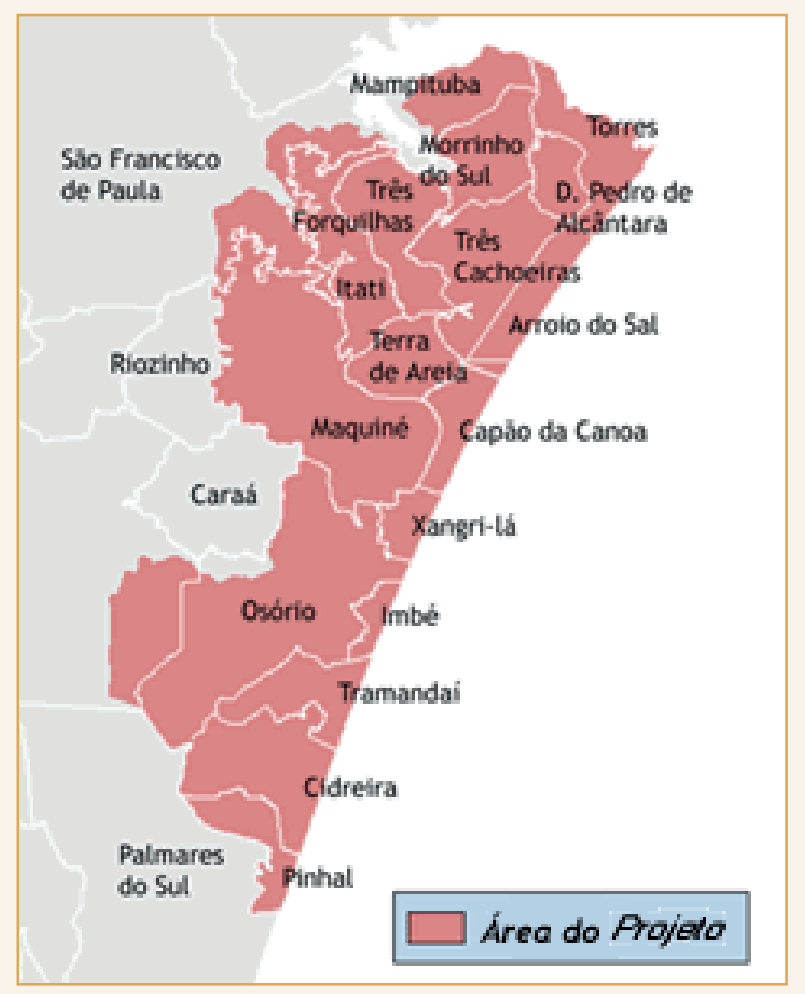

Fonte: Site oficial da FEPAM.
Segundo a Secretária Estadual de Turismo (SETUR, 2012) Torres é o destino turístico mais expressivo do estado do Rio Grande do Sul, contendo $40 \%$ dos meios de hospedagem do litoral norte do RS, mas mesmo assim, sofre com a sazonalidade e a pouca procura de turistas no inverno, como veremos a seguir.

\section{Torres}

A paisagem da cidade se destaca por ser a única praia do Rio Grande do Sul em que sobressaem paredões rochosos à beira-mar, excelente para observação de animais marinhos e embarcações. (PREFEITURA MUNICIPAL DE TORRES, 2006). Ainda segundo a Prefeitura de Torres, durante o período do verão, entre os meses de dezembro e fevereiro, o município tem um fluxo turístico de 400mil pessoas, sendo que conforme dados do Instituto Brasileiro de Geografia e Estatística (IBGE, 2015) a população local é 40 mil pessoas, ou seja, durante o veraneio a cidade abriga dez vezes mais pessoas do que a sua população fixa.

Torres possui diversos pontos turísticos, em sua maioria voltados a natureza, como a Lagoa do Violão, que está situada no centro da cidade e serve para a realização de diversos esportes aquáticos. Há a Praia Molhes, local que costuma ser um dos pontos principais da cidade para banho e surfistas, o local já conta com uma boa infraestrutura turística. A Praia da Guarita se localiza entre falésias e já é uma área de proteção ambiental, outro local já protegido é a llha dos Lobos, que é uma ilhota habitada por lobos e leões marinhos em descanso durante seu percurso de migração, no local é possível apenas circular de barco, sendo proibido desembarque e/ou atividade de pesca ou prática de surf. (PREFEITURA MUNICIPAL DE TORRES, 2016)

Quanto à observação de baleias, após participar no ano de 2014 de um evento na cidade uruguaia de Punta del Este, para discussões sobre a criação de uma "Rota Internacional das Baleias Francas" e manifestar o interesse de fazer parte desta rota, em julho de 2016, a Prefeitura Municipal de Torres, anunciou que através de parceria com as Organizações Não Governamentais - ON- 
Gs, Instituto Oceano Vivo e Instituto Augusto Carneiro, receberam um projeto para implantação da atividade de observação de baleias, patrocinado pela Fundação Boticário. (PREFEITURA MUNIClPAL DE TORRES, 2016)

De acordo com o a Prefeitura de Torres, a cidade conta, no período de julho a novembro, com a visitação de baleias francas nos mares da cidade. O local torna-se lar das baleias francas que vão até lá em busca de águas mais quentes para procriação, nascimento e amamentação de seus filhotes. As baleias podem ser vistas de diversos locais da cidade, sendo o que possui o acesso mais fácil o Morro do Farol, conforme exposto na figura 4. Local que permite a visualização de todas as praias da cidade. (PREFEITURA MUNICIPAL DE TORRES, 2016).

Figura 4 - Foto do possível local para a implantação do observatório (Parque Municipal da Guarita)

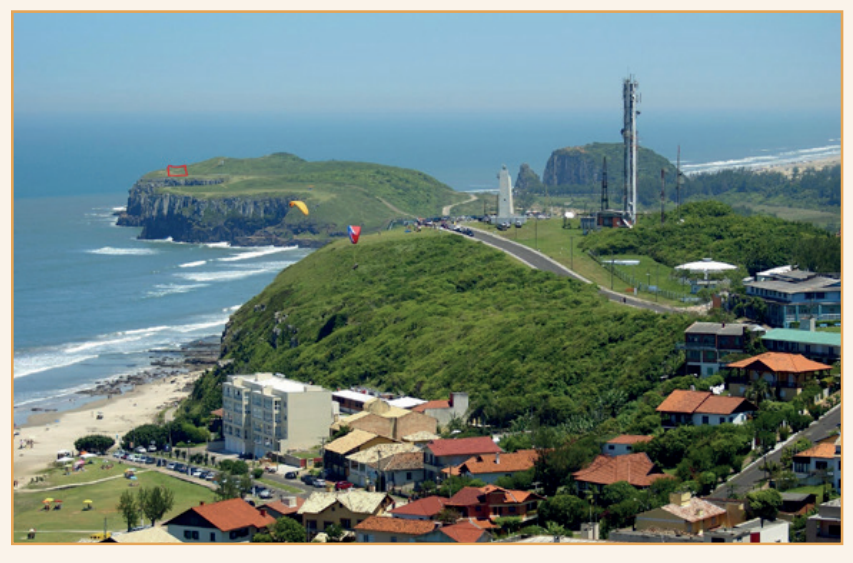

Fonte: Prefeitura Municipal de Torres

Tendo em vista o combate a sazonalidade do litoral gaúcho, podemos citar, também, outra importante cidade litorânea no Rio Grande do Sul, Imbé, a seguir será realizada a caracterização da mesma.

\section{Imbé}

Segundo a Prefeitura Municipal de Imbé (2005), a localidade tornou-se município em 09 de maio de 1988, emancipado de Tramandaí. $\bigcirc$ local está situado no Litoral Norte gaúcho, com área de 39,13 Km2. Faz divisa ao sul com Tramandaí, ao norte e a oeste com Osório e, a leste, com - Oceano Atlântico. Segundo dados do IBGE (IBGE, 2013), a população fixa de Imbé é de 17.610 mil habitantes, enquanto que no período de verão a população passa a ser de aproximadamente 160.000 mil pessoas.

Ainda segundo a prefeitura, hoje em dia, Imbé conta com 11 pontos turísticos no município, tais como: Lago braço morte, Praia, Castelinho, Dunas, Ponte Giuseppe Garibaldi, Pórtico de entrada, alameda dos eucaliptos, Alameda das Acácias, Ceclimar e o Parque de Eventos. Além destes pontos turísticos no município, imbé conta com um evento durante ano, festa da Anchova realizada no mês de Novembro.

Em 2014, junto com o município de Torres, Imbé se tornou oficialmente Rota Internacional da Baleia Franca, através de um congresso sobre as rotas e locais de preservação da baleia Franca realizado em Punta Del Este do Uruguai. De acordo com a Prefeitura da cidade, todo ano no período entre julho a setembro, turistas, moradores locais e pesquisadores vão até a beira da praia de Imbé observar a passagem dos mamíferos, porem não há um local específico para a observação, assim acabam utilizando as dunas. (PREFEITURA MUNICIPAL DE IMBÉ, 2015).

Diante destas considerações e reconhecimento inicial quanto ao objeto de estudo, é que buscamos a averiguação da efetividade das ações, e estado de desenvolvimento e articulação local, para que a potencialidade desta atividade possa ser evidenciada. Desta forma, no próximo capítulo apresentamos a descrição dos procedimentos metodológicos adotados para a viabilização desta pesquisa.

\section{Procedimentos metodológicos}

O procedimento metodológico aplicado foi uma pesquisa de natureza qualitativa, que segundo o autor Triviños (2011), é basicamente descritiva, e para alcançar os resultados esperados, foi feita uma coleta de dados, que de acordo com o autor serve para a criação de "um conjunto de conceitos, princípios e significados". (2011, p. 
130). A forma de analise escolhida no projeto foi á qualitativa na qual não se preocupa com a representatividade numérica (quantificados) e sim com a qualidade e aprofundamento da pesquisa realizada e possuí como característica, o método da entrevista como forma de coleta de dados explica Gerhardt (2009).

No procedimento de coleta de dados foi realizada uma entrevista semi-estruturada, conforme Dencker (1998). Para a seleção dos atores a serem pesquisados, que atendessem ao objetivo geral da pesquisa, iniciamos aproximação com a área de estudo através de um levantamento bibliográfico. No qual abrange fontes primárias, que de acordo com Dencker (1998) trata de materiais encontrados em revistas, produções acadêmicas e livros, por exemplo, o que nos leva a apontar que não foi encontrado nenhum estudo da área do Turismo com temática semelhante a aqui proposta, o que reforça a relevância desta pesquisa.

Este estudo inicial nos deu elementos para a definição do universo da pesquisa, bem como da amostra necessária, o que nos levou a optar pela amostragem intencional e não probabilística. Segundo Gil (2008) depende unicamente de critérios do pesquisado normalmente aplicada a estudos exploratórios e qualitativos, possibilitando o pesquisador a opção de escolha dos elementos de acesso.

Inicialmente estavam previstas entrevistas com a SETEL, a Secretaria Estadual de Lazer Esporte e Turismo - Prefeitura Municipal de Torres e da Secretaria Municipal de Turismo e Secretaria do Meio Ambiente, o Centro Nacional de Conservação da Baleia Franca, observatório específico de baleias localizado em Imbituba - SC e com atores atuantes no desenvolvimento do segmento de TOB, como os representantes do projeto TOB Terra. Porém foram viabilizadas as entrevistas presencias com a Secretaria Municipal de Turismo de Torres, a Secretaria Municipal do Meio Ambiente de Imbé. Já com a ONG TobTerrra as entrevistas foram coletadas via e-mail, por opção da coordenadora do projeto, em virtude de sua agenda. Cabe ressaltar a inclusão da Prefeitura de Imbé, pois o local está na rota internacional das Baleias Francas e possui projeto para a construção de um observatório. Foi através das conside- rações, metodologia e instrumentos citados que se procurou chegar a resposta do problema da pesquisa e dos objetivos.

\section{Resultados e considerações finais}

O presente trabalho teve como objetivo geral, averiguar a possibilidade de inserção da observação de baleias como uma atividade de ecoturismo na cidade de Torres e Imbé. Para alcançar os resultados, foram realizadas entrevistas com órgãos públicos e com atores do seguimento. Para facilitar o alcance, o trabalho teve como eixos norteadores três objetivos específicos.

O primeiro objetivo buscou investigar e relatar as atividades de ecoturismo, já existentes e comercializadas nas cidades de Torres e Imbé. Através das entrevistas realizadas, foi constado que em conformidade com os conceitos de Ecoturismo apontados pelos autores estudados, Telles (2001) e Pires (2002). Ambas as cidades possuem atividades voltadas à prática do Ecoturismo, como, passeios de barcos, caminhadas ecológicas, esportes aquáticos, tais como o surf, remo. Porém são atividades com uma demanda maior no período de verão, nos meses de dezembro a março.

No segundo objetivo, a pesquisa visa apurar quanto à implantação de um observatório de baleias. Torres e Imbé já possuem projetos para a implantação do mesmo, porém para as duas cidades estão faltando recursos financeiros.

No projeto do município de Imbé, a entrevista realizada, permitiu identificar que o observatório está projetado para ser instalado próximo aos molhes (divisa com o município de Tramandai) no formato de uma passarela de sete metros de altura e contará com equipamentos para melhor observar os mamíferos. Já em Torres, o observatório contará com a construção de uma estrutura em um dos morros do Parque da Guarita. O planejamento destas estruturas, vai ao encontro do defendido por Carvalho (1978), que aponta que a construção de tais espaços destinados a esta atividade são elementos facilitadores para a melhoria da prática da observação dos animais, sem que haja um impacto ambiental e, também, garantin- 
do a segurança dos observadores.

O terceiro objetivo buscou analisar a viabilidade de observação de baleias como um atrativo turístico em potencial e de alternativa a sazonalidade para os municípios, nos meses de maio a setembro. Nas entrevistas realizadas, percebeu-se que tanto em Torres quanto em Imbé, por se tratar de cidades litorâneas localizadas no sul do Brasil em seu período de inverno, sofrem com a diminuição populacional e de renda ocasionada pelo aporte dos turistas. Segundo os entrevistados, e que também vai ao encontro do defendido pela WWF (2003) o turismo de observação de baleias por terra, é uma alternativa para se combater a sazonalidade temporária do local, consolidação econômica, conservação ambiental, valorização da cultura, além de gerar novos postos de trabalho para os autóctones.

Desta forma, quanto ao problema da pesquisa, que questionava a potencialidade para o desenvolvimento do Ecoturismo através do Turismo de Observação de Baleias no litoral norte do Rio Grande do Sul, foi possível identificar, pontos fortes e fracos. Como ponto forte, os entrevistados relatam que há viabilidade para este segmento do turismo, pois ambas as cidades estão na rota internacional da baleia Franca, e possuem projetos para a implantação desta prática como mais um atrativo turístico local. Porém, como ponto fraco, segundo análise dos relatos, no momento, não é possível implantar um observatório nos municípios apontados. Pois segundo os entrevistados, representantes do poder público local e responsável pelo tema, apesar de ambas as cidades possuírem projeto, não há recursos para a construção das estruturas planejadas. Sendo assim não viabilizando a implantação dos projetos no momento.

Entretanto podemos citar o Tobterra como um exemplo de projeto bem sucedido. O mesmo realiza suas ações através de caminhadas e trilhas guiadas por especialistas de diversas áreas e há também, a inclusão da comunidade local, o que corrobora com a informação de Neiman e Rabinovici (2002), que descreve essa iniciativa de inserção como um contribuinte a melhoria da qualidade de vida da comunidade. Além de oferecer aos visitantes uma experiência diferenciada.

Sendo assim, podemos considerar que Torres possui um diferencial que torna a prática da observação de baleias mais viável, que são os morros localizados na beira do mar, Morro do Farol e Parque da Guarita. Tendo em vista que eles já possuem lugares altos que são próximos a Rota Internacional das baleias. Sendo assim, sugere-se que o projeto seja posto em prática á curto prazo e de maneira experimental, apenas com equipamentos que facilitem a visão dos animais, como por exemplo, binóculos. Com turmas orientadas por Guias de Turismo, ou Condutores Locais, preparados e ligados à educação ambiental, assim impactando o menos possível no ambiente. Além disso, como foi relatado pelo entrevistado e pela Prefeitura Municipal de Torres (2006), o município já possui atividades ligadas ao Ecoturismo, como caminhadas interligadas entre o Morro do Farol e o Parque Municipal da Guarita e passeios de barcos.

Por meio da realização desta pesquisa e do conhecimento adquirido através dos autores estudados e citados, compreende-se a importância da atividade relacionada ao Ecoturismo, como uma estratégia para combater a sazonalidade em determinados lugares, bem como aumentar a renda dos moradores locais gerando novos postos de trabalho e promover a cidade.

Dessa forma, sugere-se a ampliação deste estudo por outros estudantes da área do Turismo, Biologia, Oceanografia e outras áreas do conhecimento. Bem como uma investigação junto aos moradores locais e turistas, de modo que novos pontos de vista possam contribuir para a correta implantação do observatório de baleias. 


\section{Referências}

ACAPRA. Berçário das baleias francas santa catarina | brasil. Disponível em: <http://acaprasc.wixsite.com/ baleiafranca>. Acesso em: 22 de out. 2016.

BRASIL. Ministério do Turismo. Orientações Básicas, 2006. Disponível em: http://www.turismo.gov.br/sites/ default/turismo/o_ministerio/publicacoes/downloads_publicacoes/Ecoturismo_Versxo_Final_IMPRESSxO_.pdf Acesso em: 20 de out. 2016.

BRASIL, Ministério Do Turismo. Novo roteiro de ecoturismo permite observação de baleias francas em santa Catarina 2016. Disponível em: <http://www.turismo.gov.br/ultimas-noticias/6421-novo-roteiro-de-ecoturismopermite-observa\%c3\%a7\%c3\%a3o-de-baleias-franca-em-santa-catarina-2.html>. Acesso em: 02 set. 2016.

BRASIL, Ministério Do Turismo. Observação de baleias é atração no litoral do país. Disponível em:

<http://www.turismo.gov.br/ultimas-noticias/4643-observacao-de-baleias-e-atracao-no-litoral-do-pais.html>. Acesso em: 02 set. 2016.

BRASIL, Ministério Do Turismo. Começa temporada de observação de baleias-jubarte na bahia. Disponível em: <http://www.turismo.gov.br/ultimas-noticias/5251-come\%c3\%a7a-temporada-de-observa\%c3\%a7\%c3\%a3o-debaleias-jubarte-na-bahia.html>. Acesso em: 18 out. 2016.

BRUMATTI, P.N.M. Análise das potencialidades do desenvolvimento sustentável do turismo de observação de baleias, Whale Watching, na costa da Bahia, Brasil. Ilhéus, 2008.

CARVALHO, J.C.M. Atlas da fauna brasileira. São Paulo: Melhoramentos, 1978.

CECLIMAR. Zona de convergência Subtropical 2012. Disponível em: <http://www.ufrgs.br/ceclimar/ceram/faunamarinha-e-costeira>

CORBELLI, C. An evaluation of the impact of commercial Whale Watching on Humpback whales, Megaptera novaeangliae, in Newfoundland and Labrador, and of the effectiveness of a voluntary code of conduct as a management strategy. Inglaterra, UK. 2006.

CID, Jisleyangela Freitas. Educação ambiental e turismo. Revista turismo, 2005.Disponível em: <http://www. revistaturismo.com.br/artigos/educacaoambiental.html>.Acesso em: 03 set. 2016.

DENCKER, A. F. M. Métodos e técnicas de pesquisa em turismo. - São Paulo: Futura, 1998.

DIAS, G. F. Educação ambiental: princípios e práticas. São Paulo: Gaia, 2003.

DENCKER. A. F. M. Métodos e técnicas de pesquisa em turismo: subtítulo do livro. 2 ed. SÃO PAULO: FUTURAR, 1998. p 179

DIARIO CATARINENSE. Disputa judicial atrasa liberação do turismo de observação de baleias em barcos. Disponível em: <http://dc.clicrbs.com.br/sc/estilo-de-vida/noticia/2016/06/disputa-judicial-atrasa-liberacao-doturismo-de-observacao-de-baleias-em-barcos-6044144.html>. Acesso em: 05 out. 2016.

DIARIO CATARINENSE. Proibição de turismo de observação de baleias passa por mais uma etapa. Disponível em: <http://dc.clicrbs.com.br/sc/noticias/noticia/2014/06/proibicao-de-turismo-de-observacao-de-baleiaspassa-por-mais-uma-etapa-4516397.html>. Acesso em: 14 out. 2016.

FEPAM, FUNDAÇÃO ESTADUAL DE PROTEÇÃO AMBIENTAL HENRIQUE LUIZ ROESSLER. Programas e Projetos: GERCO/RS, 2017. 
Revista Científica Digital - Publicidade e propaganda, Jornalismo e Turismo | Junho de 2018

GEHARDT, T. E. Métodos de pesquisa. Porto Alegre, p.31 abr. 2009. Disponível em: http://www.ufrgs.br/ cursopgdr/downloadsSerie/derad005.pdf>. Acesso em: 06 mai. 2017.

GIL, A. C. Métodos e técnicas de pesquisa social. São paulo, p.90-2008. Disponível em: < file:///C:/Users/ gabriel/Downloads/metodologia-gil-PDF\%20(1).pdf >. Acesso em: 2 nov. 2016.

GREENPEACE. Santuário de baleias. Disponível em: <http://www.greenpeace.org.br/santuariodasbaleias?gclid $=c j i q o 8 p s 5 \mathrm{~m} 8$ cfvdahgod8owcna $>$. Acesso em: 14 out. 2016

GUERRRA, C. Turismo embarcado. In: CAGNINI, Lariane. Disputa judicial atrasa liberação do turismo de observação de baleias em barcos. Imbituba, SC: Diário Catarinense, 19 jun. 2016. Disponivél em: <http:// dc.clicrbs.com.br/sc/estilo-de-vida/noticia/2016/06/disputa-judicial-atrasa-liberacao-do-turismo-de-observacaode-baleias-em-barcos-6044144.html>. Acesso em:15 out. 2016.

HOYT, E. Whale Watching Takes Off. Journal of The American Cetacean Society Whale Watcher,1995.

HOYT, E. Whale Watching 2001: Worldwide tourism numbers, expenditures and expanding socioeconomic benefits. MA, USA. 2001

INSTITUTO CHICO MENDES DE CONSERVAÇÃO DA BIODIVERSIDADE . Area de proteção ambiental da baleia franca. Disponível em: <http://www.icmbio.gov.br/apabaleiafranca/destaques.html>. Acesso em: 05 nov. 2016.

JACOBINA, A. M. S. Os cetáceos, 2000. Disponível em: <http://repositorio.uniceub.br/jspui/ bitstream/123456789/2396/2/9658355.pdf>.Acesso em: 01 out. 2016

LARA ELY. Rs terá rota turística para observação de baleias a partir do próximo semestre 2015. Disponível em:http://zh.clicrbs.com.br/rs/noticias/planeta-ciencia/noticia/2015/08/rs-tera-rota-turistica-para-observacao-debaleias-a-partir-do-proximo-semestre-4815581.html>. Acesso em: 31 ago. 2016.

MÔNICA CARDOSO. Observação de baleias. Disponível em: <http://turismo.ig.com.br/destinos-internacionais/ observacao-de-baleias-pelo-mundo/n1597220126783.html>. Acesso em: 28 ago. 2016.

MULLER, G. A. O turismo e sua relação com a educação ambiental.. 19, out. 2012. Disponível em: <file:///c:/ users/gabriel/documents/plannat14.pdf>.Acesso em: 03 set. 2016.

NEIMAN, Z; RABINOVICl. O cerrado como instrumento para educação ambiental em atividades de ecoturismo: Manole, 2002.

ORGANIZAÇÃO MUNDIAL DO TUISMO (OMT) 2012. Disponível em: https://ajonu.org/2012/10/17/organizacaomundial-do-turismo-omt/

OLIVEIRA, T. G.; CASSARO, K. Guia de identificação dos felinos brasileiros. São Paulo: Fundação Parque Zoológico de São Paulo, 1997

O ECOTURISMO. Observação de fauna. Disponível em: <http://oecoturismo.blogspot.com.br/2015/02/oecoturismo-e-um-dos-segmentos.html>. Acesso em: 18 ago. 2016.

PALAZZO. J. T. Atlântico sul: um santuário de baleias. 2016. Disponível em: <http://www.baleiafranca.org.br/ oprojeto/publicacoes/santuarioatlanticosul.pdf>.Acesso em: 22 agosto. 2016.

PREFEITURA MUNICIPAL DE IMBÉ. Pontos turísticos. Disponível em: http://www.imbe.rs.gov. $\mathrm{br} /$ ?titulo=Turismo\&template $=$ conteudo\&categoria $=812 \&$ codigoCategoria=812. Acesso em: 07 mai. 2017

PREFEITURA MUNICIPAL DE TORRES. Conheça torres.. Disponível em: <http://www.torres.rs.gov.br/index.php/ conheca-torres $>$. Acesso em: 15 out. 2016 
PREFEITURA MUNICIPAL DE TORRES. Torres está na rota internacional das baleias francas. Disponível em: <http://www.torres.rs.gov.br/index.php/secretaria-de-meio-ambiente/73-secretarias-e-orgaos/ secretaria-do-meio-ambiente-e-urbanismo/2052-torres-esta-na-rota-internacional-das-baleias-francassera-um-observatorio-de-baleias>. Acesso em: 30 set. 2016. http://www.cidades.ibge.gov.br/xtras/perfil. php?codmun $=432150 \&$ search\&lang $=$

REDE WEB DE COMUNICAÇÃO. Turismo de observação de baleias por terra garantem uma experiência única. 11 ago. 2016. Disponível em: < http://www.portalrwc.com.br/noticia/2016/08/11/Turismo-deobserva\%C3\%A7\%C3\%A3o-de-baleias-por-terra-garantem-uma-experi\%C3\%AAncia-\%C3\%BAnica>. Acesso em : 15 out. 2016.

ROE, D.; WILLIAMS, N.L.; CLAYTON, B.D.Take only photographs, leave only footprints: the environmental impacts of wildlife tourism. London: The International Institute for Environment and Development, 1997.

SECRETARIA DE TURISMO DE TORRES. Competitividade turística cresceu em torres. Disponível em: <http:// www.torres.rs.gov.br/index.php/component/content/article/25-secretarias-e-orgaos/secretaria-turismocomercio-industria/781-competitividade-turistica-cresceu-em-torres?highlight=ytoxontpoja7czo4oijwcm9qzxrvcy $i 7 \mathrm{f}==>$. Acesso em: 30 set. 2016

TURISMO DESTINOS INTERNACIONAIS. Observação de baleias. Disponível em: <http://turismo.ig.com.br/ destinos-internacionais/observacao-de-baleias-pelo-mundo/n1597220126783.html>. Acesso em: 22 ago. 2016.

TOB TERRA. Rede de turismo de observação de baleias por terra (tobterra) inicia temporada 2016. Disponível em: <http://www.garopabamidia.com.br/noticias/titulo/8403/rede-de-turismo-de-observaasectapoundo-debaleias-por-terra-tobterra-inicia-temporada-2016>. Acesso em: 19 out. 2016http://noticias.ufsc.br/2016/07/asbaleias-francas-do-sul-sao-a-esperanca-de-salvacao-da-especie/

TRIVIÑOS, A. N. S. Introdução a pesquisa em ciências sociais: a pesquisa qualitativa em educação. - 1. Ed. - 20 Reimpr. São Paulo: Atlas, 2011

UNEP/CMS.United Nations Environment Programme and Conservation of Migratory Species of Wild Animals. Wildlife Watching and Tourism: A study on the benefits and risks of a fast growing tourism activity and its impacts on species.UNEP / Germany. 2006.

WWF. World Wide Found for Nature Santuário de baleias do atlântico sul. 2016 Disponível em: <http://www.wwf. org.br/?53502>. Acesso em: 13 out. 2016.

SETUR, SECRETARIA DE ESTADO DO TURISMO DO RIO GRANDE DO SUL. Plano de Desenvolvimento do Turismo do Rio Grande do Sul: 2012-2015 